\title{
Deteriorated Systolic Blood Pressure Recovery and Heart Rate Recovery After Graded Exercise in Children With Familial Mediterranean Fever
}

\author{
Havva EVRENGÜL, ${ }^{1}$ Selçuk YÜKSEL, ${ }^{2}$ Mustafa DOĞAN, ${ }^{3}$ Dolunay GÜRSES, ${ }^{3}$ Harun EVRENGÜL ${ }^{4}$ \\ ${ }^{1}$ Department of Pediatric Nephrology, Medical Faculty of Pamukkale University, Denizli, Turkey \\ ${ }^{2}$ Department of Pediatric Rheumatology, Medical Faculty of Pamukkale University, Denizli, Turkey \\ ${ }^{3}$ Department of Pediatric Cardiology, Medical Faculty of Pamukkale University, Denizli, Turkey \\ ${ }^{4}$ Department of Cardiology, Medical Faculty of Pamukkale University, Denizli, Turkey
}

\begin{abstract}
Objectives: This study aims to investigate if cardiac involvement may occur in children with familial Mediterranean fever (FMF) without cardiovascular symptoms by using heart rate recovery (HRR) and systolic blood pressure recovery (SBPR) parameters.

Patients and methods: A total of 50 FMF patients ( 26 males, 24 females; mean age $151 \pm 33.4$ month; range 60 to 216 month) and 30 healthy controls (18 males, 12 females; mean age $143 \pm 43.9$ month; range 84 to 228 month) were included in the study. All patients were evaluated by echocardiography. All patients underwent a maximal graded exercise stress test. HRR and SBPR parameters were calculated.

Results: There was a significant decrease in HRR1 value in FMF group ( $p=0.03$ ). SBPR1 and SPBR2 values were higher in FMF group compared to control group $(0.96 \pm 0.12$ vs $0.88 \pm 0.12$ and $0.95 \pm 0.09$ vs $0.91 \pm 0.11$, respectively); and the high SBPR1 value was statistically significant ( $p=0.02)$. FMF presence had a negative correlation with HRR1 $(r=-0.26, p=0.03)$ and a positive correlation with SBPR1 ( $r=0.29, p=0.02)$. There was a negative correlation of M694V homozygous mutation with HRR1 and HRR2 values $(r=-0.43, p=0.004, r=-0.42, p=0.005)$.

Conclusion: Cardiac involvement may occur in FMF patients without cardiovascular symptoms. Impaired SBPR and decreased HRR response may indicate increased cardiovascular risk in these patients despite normal exercise stress test results.

Keywords: Autonomic dysfunction; Familial Mediterranean fever; heart rate recovery; systolic blood pressure recovery.
\end{abstract}

Familial Mediterranean fever (FMF) is an autosomal recessive auto inflammatory disease characterized by recurrent fever attacks and inflammation of the serous membranes (peritonitis, pleuritis, pericarditis, arthritis, etc.). ${ }^{1}$ Cardiovascular involvement is one of the major causes of mortality and morbidity in patients with FMF. ${ }^{2}$

The exercise stress test has been used to assess the cardiovascular performance of patients. Besides exercise capacity and chronotropic response, heart rate recovery (HRR) index and systolic blood pressure recovery (SBPR) rate can be calculated by the exercise stress test. ${ }^{3,4}$ A normal HRR response occurs as a result of a balance between sympathetic and parasympathetic systems. The presence of abnormal HRR has been shown to be an independent marker of mortality. Increased sympathetic activity and delayed HRR response due to insufficient vagal reactivation have been shown as autonomic dysfunction findings in FMF patients. ${ }^{5,6}$ SBPR can be obtained by determining the ratio of the third-minute systolic blood pressure of the recovery period to peak exercise systolic blood pressure, or the first-minute systolic blood pressure. It represents the reduction in systolic blood pressure after exercise. ${ }^{7,8} \mathrm{~A}$ delay in the 
reduction of systolic blood pressure after exercise is an abnormal response and has been associated with increased cardiovascular risk. ${ }^{9}$ There have been studies in the literature demonstrating abnormal HRR findings in FMF patients. To the best of our knowledge, no study has been conducted on individuals with FMF using SBPR, which is known to be associated with increased cardiovascular risk. Therefore, in this study, we aimed to investigate if cardiac involvement may occur in children with FMF without cardiovascular symptoms by using HRR and SBPR parameters.

\section{PATIENTS AND METHODS}

This study was conducted by the Pamukkale University's Medical Faculty Pediatric Rheumatology Department and Cardiology Department between January 2015 and June 2015. A total of 50 patients (26 males,

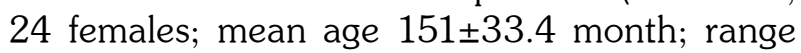
60 to 216 month) who were not in attack period and were being followed-up with a FMF diagnosis according to Tel Hashomer and a new set of criteria for children ${ }^{10,11}$ were included. In addition, 30 healthy controls (18 males, 12 females; mean age $143 \pm 43.9$ month; range 84 to 228 month) with no cardiologic or rheumatologic problems were included. Those with comorbid secondary chronic rheumatic problems to a FMF diagnosis were excluded. The onset age of disease, disease duration, clinical findings (fever, abdominal pain, chest pain, joint pain, and rash), dose and duration of medication, and Mediterranean fever mutation were recorded for each patient. All patients were evaluated by echocardiography before the study to eliminate congenital heart defects. The study protocol was approved by the Pamukkale University's Medical Faculty Ethics Committee. The study was conducted in accordance with the principles of the Declaration of Helsinki.

The patients and control group underwent a maximal graded exercise stress test using a Quinton treadmill system with the modified Bruce technique developed for children. ${ }^{12}$ The 12-lead electrocardiographic monitorization was performed continuously during the test. Blood pressure and heart rate were measured automatically using a Tango exercise blood pressure-monitoring device before every stage and at the second minute in every stage of the exercise stress test. Maximal target heart rate during the exercise stress test was calculated as subtraction of age (year) from 220. The exercise stress test was continued until reaching $95 \%$ of the maximal heart rate. The HRR differences within the first five minutes after exercise (HRR1, HRR2, HRR3, HRR4, and HRR5) were calculated by subtracting the heart rate at each minute from the maximal heart rate. The ratio of the third-minute systolic blood pressure (SBP) of recovery period to peak SBP was considered to be SBPR1. Additionally, the ratio of the third-minute $\mathrm{SBP}$ of recovery period to the first-minute SBP was considered to be SBPR2. ${ }^{8}$ When the exercise capacity reached peak exercise, it was calculated as the total metabolic equivalent units.

\section{Statistical analysis}

All data were evaluated using the SPSS version 16.0 software (SPSS Inc., Chicago, IL, USA). Continuous variables were expressed as mean \pm standard deviation and categorical variables were expressed as percentages. The Chi-square test and unpaired t test were used for evaluating comparisons of categorical and continuous variables between the two groups. Correlations between HRR and SBPR parameters were calculated by the Pearson's correlation analysis. A $p$ value of $\leq 0.05$ was considered statistically significant.

\section{RESULTS}

All of the children's growth-development and physical examinations were normal. The mean age, height, and weight of FMF and control groups were similar ([151 \pm 33.4 month, $143 \pm 43.9$ month $\mathrm{p}=0.46],[151 \pm 15.9 \mathrm{~cm}, 148 \pm 17.5 \mathrm{~cm}$ $\mathrm{p}=0.46]$, and [ $44.5 \pm 14.6 \mathrm{~kg}, 42.6 \pm 15.2 \mathrm{~kg} \mathrm{p}=0.5]$, respectively). The most common clinical symptoms observed in the FMF group were abdominal pain $(86 \%)$ and fever (62\%). The clinical findings of FMF are presented in Table 1. All patients underwent genetic analysis for the Mediterranean fever mutation. The M694V mutation was the most commonly obtained mutation (32\%). Comparison of the exercise stress test parameters of FMF and control groups is summarized in Table 2. Although all HRR parameters obtained were lower in the FMF group compared to the control group, there 


\begin{tabular}{|lccr|}
\hline $\begin{array}{l}\text { Table 1. Demographic and clinical features of } \\
\text { Mediterranean fever }\end{array}$ & $\mathrm{n}$ & $\%$ & Mean $\pm \mathrm{SD}$ \\
\hline & & & $151 \pm 33.4$ \\
\hline Age (month) & & & $151.4 \pm 15.9$ \\
Height (centimeter) & & & $44.5 \pm 14.6$ \\
Weight (kg) & & & $100 \pm 39$ \\
Age at diagnosis (month) & & & $49.9 \pm 26.8$ \\
Disease duration (month & & & $1.1 \pm 0.21$ \\
Dose of colchicine (mg/day) & 31 & 62 & \\
Clinical manifestation & 43 & 86 & \\
$\quad$ Fever & 1 & 2 & \\
Abdominal pain & 1 & 2 & \\
Chest pain & 16 & 32 & \\
Rash & & & \\
$\quad$ Arthritis/arthralgia & 20 & 40 & \\
Mutation & 11 & 22 & \\
$\quad$ Homozygous & 17 & 34 & \\
Heterozygous & 2 & 4 & \\
Compound heterozygous & & & \\
$\quad$ No mutation & &
\end{tabular}

was a significant decrease in the HRR1 value $(p=0.03)$. In addition, the SBPR1 and SPBR2 values obtained were higher in the FMF group compared to the control group $(0.96 \pm 0.12$ vs. $0.88 \pm 0.12$ and $0.95 \pm 0.09$ vs. $0.91 \pm 0.11$, respectively); and the high SBPR1 value was statistically significant $(p=0.02)$. Other exercise stress test parameters were similar between both groups.

The FMF clinical findings and correlation analysis results among the exercise stress test parameters are summarized in Table 3 . The FMF presence had a negative correlation with HRR1 $(\mathrm{r}=-0.26, \mathrm{p}=0.03)$, but a positive correlation with
SBPR1 $(r=0.29, p=0.02)$. Moreover, there was a negative correlation of the M694V homozygous mutation with the HRR1 and the HRR2 values $(\mathrm{r}=-0.43, \mathrm{p}=0.004 ;$ and $\mathrm{r}=-0.42, \mathrm{p}=0.005)$. There was no correlation of the HRR and the SBPR values with age and daily dose of colchicine.

\section{DISCUSSION}

In this study, we detected deteriorated exercise stress test parameters in children with FMF.

Table 2. Comparison of exercise stress test characteristics between patient and control groups

\begin{tabular}{|c|c|c|c|}
\hline & FMF patients & Controls & \\
\hline & Mean \pm SD & Mean \pm SD & $p$ \\
\hline Exercise capacity (METs) & $11 \pm 1.5$ & $11.1 \pm 1.3$ & 0.745 \\
\hline Preexercise SBP (mmHg) & $118 \pm 14.6$ & $117 \pm 18$ & 0.813 \\
\hline Preexercise DBP (mmHg) & $75 \pm 13$ & $73 \pm 13$ & 0.711 \\
\hline Peak exercise HR, beats/min & $172 \pm 17$ & $173 \pm 17$ & 0.804 \\
\hline Peak SBP (mmHg) & $132 \pm 21$ & $137 \pm 18$ & 0.330 \\
\hline Peak DBP (mmHg) & $74 \pm 14$ & $68 \pm 16$ & 0.213 \\
\hline Recovery SBP $1^{\text {st }} \min (\mathrm{mmHg})$ & $133 \pm 21$ & $132 \pm 19$ & 0.893 \\
\hline Recovery SBP $3^{\text {rd }} \min (\mathrm{mmHg})$ & $125 \pm 15$ & $119 \pm 15$ & 0.148 \\
\hline SBPR1 & $0.96 \pm 0.12$ & $0.88 \pm 0.12$ & 0.020 \\
\hline SBPR2 & $0.95 \pm 0.09$ & $0.91 \pm 0.11$ & 0.17 \\
\hline HRR $1^{\text {st }} \min$, beats $/ \mathrm{min}$ & $48 \pm 14$ & $57 \pm 20$ & 0.035 \\
\hline HRR $2^{\text {nd }} \mathrm{min}$, beats $/ \mathrm{min}$ & $63 \pm 13$ & $71 \pm 20$ & 0.077 \\
\hline HRR $3^{\text {rd }} \mathrm{min}$, beats $/ \mathrm{min}$ & $65 \pm 13$ & $71 \pm 17$ & 0.110 \\
\hline HRR $4^{\text {th }} \mathrm{min}$, beats $/ \mathrm{min}$ & $67 \pm 11$ & $72 \pm 17$ & 0.203 \\
\hline HRR $5^{\text {th }} \mathrm{min}$, beats $/ \mathrm{min}$ & $69 \pm 12$ & $71 \pm 13$ & 0.531 \\
\hline
\end{tabular}


Table 3. Correlation analysis between clinical characteristics of familial Mediterranean fever patients and exercise stress test characteristics

\begin{tabular}{|c|c|c|c|c|c|c|c|c|}
\hline & \multicolumn{2}{|c|}{ Existence FMF } & \multicolumn{2}{|c|}{ Age } & \multicolumn{2}{|c|}{ Daily dose of colchicine } & \multicolumn{2}{|c|}{ M694V homozygous } \\
\hline & $\mathrm{r}$ & $p$ & $\mathrm{r}$ & $p$ & $\mathrm{r}$ & $p$ & $\mathrm{r}$ & $p$ \\
\hline SBPR1 & 0.294 & 0.020 & 0.047 & 0.715 & -0.144 & 0.416 & 0.248 & 0.090 \\
\hline SBPR2 & 0.176 & 0.172 & 0.105 & 0.417 & 0.147 & 0.405 & 0.116 & 0.428 \\
\hline HRR $1^{\text {st }} \min$, beats $/ \mathrm{min}$ & -0.269 & 0.035 & 0.080 & 0.537 & -0.074 & 0.677 & -0.430 & 0.004 \\
\hline HRR $2^{\text {nd }} \min$, beats $/ \mathrm{min}$ & -0.227 & 0.077 & 0.098 & 0.447 & 0.058 & 0.744 & -0.421 & 0.005 \\
\hline HRR $3^{\text {rd }} \min$, beats/min & -0.205 & 0.110 & 0.163 & 0.206 & 0.101 & 0.572 & -0.068 & 0.645 \\
\hline HRR $4^{\text {th }} \mathrm{min}$, beats $/ \mathrm{min}$ & -0.164 & 0.203 & 0.145 & 0.262 & 0.064 & 0.720 & -0.158 & 0.285 \\
\hline HRR $5^{\text {th }} \mathrm{min}$, beats $/ \mathrm{min}$ & -0.081 & 0.531 & 0.134 & 0.299 & 0.131 & 0.462 & -0.014 & 0.927 \\
\hline
\end{tabular}

Firstly, the HRR1 value was decreased in children with FMF compared to the control group. Secondly, the SBPR1 value was significantly increased in children with FMF. Thirdly, a negative correlation was found between FMF presence and HRR1, but a positive correlation was found between SBPR1 and FMF presence. Lastly, the presence of an M694V homozygous mutation was negatively correlated between HRR1 and HRR2 values.

The autonomic nervous system plays a major role in the regulation of cardiovascular functions. Studies in the literature have investigated the relationship between autoinflammatory diseases and cardiac autonomic dysfunction. ${ }^{13,14}$ HRR is a frequently used technique for assessing cardiac autonomic dysfunction. ${ }^{15}$ Deterioration was found in the HRR indexes of adult patients with FMF compared to healthy individuals in recent studies that $\mathrm{Ardic}^{5}$ and Canpolat et al. ${ }^{6}$ conducted. Contrary to these studies, Sahin et al. ${ }^{16}$ found no difference between groups in terms of HRR parameters in their study conducted on children patients. In our study, deterioration was found in the HRR1 value for children with FMF compared to the healthy control group. These controversial results between Sahin et al. ${ }^{16}$ and our study may arise from the different clinical and genotypical characteristics of the patient populations. While M694V mutation prevalence was $17 \%$ in their study, it was $32 \%$ in our study group. Also, the mean age of our patients was higher than in Sahin's study group.

Cardiovascular complications contribute to the morbidity and mortality rates in rheumatologic and autoinflammatory diseases. An insufficient reduction in heart rate after exercise has been shown to be a marker of autonomic dysfunction. ${ }^{17}$ In addition, it has been documented as an independent indicator of all mortalities caused by cardiovascular and other diseases. ${ }^{18,19}$ This autonomic dysfunction, characterized by insufficient vagal reactivation besides excessive sympathetic activation, has been associated with FMF. ${ }^{20,21}$ Moreover, deteriorated HRR at the first minute after exercise is a powerful marker of mortality, independent from the increased workload of the heart during exercise, and myocardial perfusion defects. ${ }^{22}$

Changes in SBPR have been proposed to be associated with sympathetic and parasympathetic activity, systemic vascular resistance, and baroreflex sensitivity. A decreased SBP ratio after exercise has been considered to be a reflection of the physical activity and general health of an individual. A greater decrease in SBP in the recovery period after peak exercise reflects that the individual's physical activity and aerobic capacity are good. This response occurs as a result of a reduction in systemic vascular resistance because exercise improves vascular endothelial function and vasodilator capability. ${ }^{23-27}$

In several recent studies, markers indicating endothelial damage, such as thrombomodulin, adrenomedullin, and nitrite, have been found to be high in FMF patients in the non-attack period as well. ${ }^{28,29}$ This finding proposes that ongoing subclinical inflammation and endothelial dysfunction are present also in the non-attack period in patients, and this is associated with increased cardiovascular problems. ${ }^{30}$ We think that endothelial and autonomic dysfunction, together with subclinical inflammation, are responsible 
for a significantly higher SBPR1 value in FMF patients compared to the control group.

Although insufficient HRR and autonomic dysfunction are well known, there has been limited information demonstrating the relationship between SBPR and the autonomic nervous system. ${ }^{31}$ Therefore, the demonstration of an insufficient SBPR1 response for the first time in FMF patients might be significant for indicating autonomic and endothelial dysfunction, which has been shown to be associated with FMF pathophysiology.

Considering the correlation analysis of clinical findings and the exercise stress test parameters of FMF patients, the presence of disease had a negative correlation with HRR1, and a positive correlation with SBPR1 also supported this finding. In addition, the negative correlation between HRR1 and HRR2 values in M694V mutation-positive patients was considered to be responsible for disease coursing with severe clinical symptoms. ${ }^{32,33}$ This suggests that M694V homozygote patients have an increased cardiovascular risk.

The exercise capacities of the patient and control groups were good. No significant difference was found in terms of exercise capacity, initial heart rate, and peak heart rate. Therefore, we suggest that insufficiency in HRR and SBPR developed due to autonomic and endothelial dysfunction.

One of the limitations of this study was the limited number of patients. In addition, we do not know the exact effect of FMF SBPR. Therefore, further studies are necessary to identify SBPR correctly after exercise stress tests in patients with FMF.

In conclusion, to our knowledge, this is the first study indicating SBPR impairment and its relationship to the HRR of patients with FMF. Cardiac involvement may occur in FMF patients without cardiovascular symptoms. FMF is associated with insufficient SBPR and delayed HRR after exercise. In our opinion, insufficient SBPR and decreased HRR response may indicate increased cardiovascular risk in these patients despite normal exercise stress tests. Further studies are necessary to demonstrate the clinical findings of deteriorated autonomic and endothelial dysfunction in FMF patients, and to explain the exact underlying pathophysiological mechanisms in autoinflammatory diseases.

\section{Declaration of conflicting interests}

The authors declared no conflicts of interest with respect to the authorship and/or publication of this article.

\section{Funding}

The authors received no financial support for the research and/or authorship of this article.

\section{REFERENCES}

1. Samuels J, Ozen S. Familial Mediterranean fever and the other autoinflammatory syndromes: evaluation of the patient with recurrent fever. Curr Opin Rheumatol 2006;18:108-17.

2. Knockaert DC. Cardiac involvement in systemic inflammatory diseases. Eur Heart J 2007;28:1797804.

3. Arai Y, Saul JP, Albrecht P, Hartley LH, Lilly LS, Cohen RJ, et al. Modulation of cardiac autonomic activity during and immediately after exercise. Am J Physiol 1989;256:132-41.

4. Savin WM, Davidson DM, Haskell WL. Autonomic contribution to heart rate recovery from exercise in humans. J Appl Physiol Respir Environ Exerc Physiol 1982;53:1572-5.

5. Ardic I, Kaya MG, Yarlioglues M, Dogdu O, Celikbilek $\mathrm{M}$, Akpek M, et al. Assessment of heart rate recovery index in patients with familial Mediterranean fever. Rheumatol Int 2011;31:121-5.

6. Canpolat U, Dural M, Aytemir K, Akdoğan A, Kaya EB, Sahiner L, et al. Evaluation of various cardiac autonomic indices in patients with familial Mediterranean fever on colchicine treatment. Auton Neurosci 2012;167:70-4.

7. Taylor AJ, Beller GA. Postexercise systolic blood pressure response: clinical application to the assessment of ischemic heart disease. Am Fam Physician 1998;58:1126-30.

8. McHam SA, Marwick TH, Pashkow FJ, Lauer MS. Delayed systolic blood pressure recovery after graded exercise: an independent correlate of angiographic coronary disease. J Am Coll Cardiol 1999;34:754-9.

9. Miyahara $\mathrm{T}$, Yokota $\mathrm{M}$, Iwase $\mathrm{M}$, Watanabe $\mathrm{M}$, Matsunami T, Koide M, et al. Mechanism of abnormal postexercise systolic blood pressure response and its diagnostic value in patients with coronary artery disease. Am Heart J 1990;120:40-9.

10. Livneh A, Langevitz P, Zemer D, Zaks N, Kees $\mathrm{S}$, Lidar $\mathrm{T}$, et al. Criteria for the diagnosis of familial Mediterranean fever. Arthritis Rheum 1997;40:1879-85. 
11. Yalçinkaya F, Ozen S, Ozçakar ZB, Aktay N, Cakar $\mathrm{N}$, Düzova $\mathrm{A}$, et al. A new set of criteria for the diagnosis of familial Mediterranean fever in childhood. Rheumatology (Oxford) 2009;48:395-8.

12. Bruce RA, Kusumi F, Hosmer D. Maximal oxygen intake and nomographic assessment of functional aerobic impairment in cardiovascular disease. Am Heart J 1973;85:546-62.

13. Akcay A, Acar G, Sayarlioglu M, Sokmen A, Kaya $\mathrm{H}$, Ispiroglu $\mathrm{M}$, et al. QT dispersion and transmural dispersion of repolarization in patients with familial Mediterranean fever. Mod Rheumatol 2009;19:550-5.

14. Aydemir M, Yazisiz V, Basarici I, Avci AB, Erbasan F, Belgi A, et al. Cardiac autonomic profile in rheumatoid arthritis and systemic lupus erythematosus. Lupus 2010;19:255-61.

15. Thomas DE, Exton SA, Yousef ZR. Heart rate deceleration after exercise predicts patients most likely to respond to cardiac resynchronisation therapy. Heart 2010;96:1385-9.

16. Sahin M, Kır M, Makay B, Keskinoğlu P, Bora E, Ünsal E, et al. Cardiac autonomic functions in children with familial Mediterranean fever. Clin Rheumatol 2016;35:1237-44.

17. Manfrini O, Pizzi C, Trerè D, Fontana F, Bugiardini R. Parasympathetic failure and risk of subsequent coronary events in unstable angina and non-STsegment elevation myocardial infarction. Eur Heart $\mathrm{J}$ 2003;24:1560-6.

18. Cole CR, Blackstone EH, Pashkow FJ, Snader CE, Lauer MS. Heart-rate recovery immediately after exercise as a predictor of mortality. $\mathrm{N}$ Engl J Med 1999;341:1351-7.

19. Mora S, Redberg RF, Sharrett AR, Blumenthal RS. Enhanced risk assessment in asymptomatic individuals with exercise testing and Framingham risk scores. Circulation 2005;112:1566-72.

20. Rozenbaum M, Naschitz JE, Yudashkin M, Rosner I, Sabo E, Shaviv N, et al. Cardiovascular autonomic dysfunction in familial Mediterranean fever. J Rheumatol 2002;29:987-9.

21. Rozenbaum M, Naschitz JE, Yudashkin M, Sabo E, Shaviv N, Gaitini L, et al. Cardiovascular reactivity score for the assessment of dysautonomia in familial Mediterranean fever. Rheumatol Int 2004;24:147-52.

22. Lind L, Andrén B. Heart rate recovery after exercise is related to the insulin resistance syndrome and heart rate variability in elderly men. Am Heart $\mathrm{J}$ 2002;144:666-72.

23. Laukkanen JA, Kurl S, Salonen R, Lakka TA, Rauramaa R, Salonen JT. Systolic blood pressure during recovery from exercise and the risk of acute myocardial infarction in middle-aged men. Hypertension 2004;44:820-5.

24. Kurl S, Laukkanen JA, Rauramaa R, Lakka TA, Sivenius J, Salonen JT. Systolic blood pressure response to exercise stress test and risk of stroke. Stroke 2001;32:2036-41.

25. Raven PB, Potts JT, Shi X. Baroreflex regulation of blood pressure during dynamic exercise. Exerc Sport Sci Rev 1997;25:365-89.

26. Hambrecht R, Wolf A, Gielen S, Linke A, Hofer $\mathrm{J}$, Erbs S, et al. Effect of exercise on coronary endothelial function in patients with coronary artery disease. N Engl J Med 2000;342:454-60.

27. Mackey RH, Sutton-Tyrrell $K$, Vaitkevicius PV, Sakkinen PA, Lyles MF, Spurgeon HA, et al. Correlates of aortic stiffness in elderly individuals: a subgroup of the Cardiovascular Health Study. Am J Hypertens 2002;15:16-23.

28. Ozbalkan Z, Ozturk MA, Onat AM, Ureten K, Haznedaroglu IC, Kiraz S, et al. Circulating thrombomodulin levels in familial Mediterranean fever. Clin Exp Rheumatol 2006;24:95-8.

29. Balat A, Işlek I, Cekmen M, Yürekli M, Tekin D, Muslu $A$, et al. Adrenomedullin and total nitrite levels in children with familial Mediterranean fever. J Paediatr Child Health 2006;42:240-3.

30. Gasparyan AY, Ugurlucan M. The emerging issue of cardiovascular involvement in familial Mediterranean fever Arch Med Sci 2008;4:465-7.

31. Alihanoglu YI, Yildiz BS, Kilic ID, Uludag B, Demirci EE, Zungur $\mathrm{M}$, et al. Impaired systolic blood pressure recovery and heart rate recovery after graded exercise in patients with metabolic syndrome. Medicine (Baltimore) 2015;94:428.

32. Gershoni-Baruch R, Brik R, Shinawi M, Livneh A. The differential contribution of MEFV mutant alleles to the clinical profile of familial Mediterranean fever. Eur J Hum Genet 2002;10:145-9.

33. Sakallioglu O, Gok F, Kalman S, Gul D, Gokcay E. The phenotype-genotype correlations of FMF patients: a single center study. Rheumatol Int 2006;26:638-40. 